\title{
Potential Solutions for Sustaining the Costs of Cancer Drugs
}

\author{
Gilberto Lopes, ${ }^{1}$ Arnold Vulto, ${ }^{2}$ Nils Wilking, ${ }^{3}$ Wim van Harten,,${ }^{4,5}$ Klaus Meier $^{6}$ and Steven Simoens ${ }^{7}$ \\ 1. Sylvester Comprehensive Cancer Center, University of Miami, FL, US; 2. Erasmus University Medical Center, Rotterdam, The Netherlands; 3. \\ Karolinska Institutet, Solna, Sweden; 4. Rijnstate Hospital, Arnhem, The Netherlands; 5 . University Twente, Enschede, The Netherlands; 6. HKK \\ Soltau, Lower Saxony \& Heidekreis-Klinikum GmbH, Soltau, Germany; 7. KU Leuven, Leuven, Belgium
}

$\mathrm{T}$ he growing burden of cancer urgently requires sustainable solutions to ensure continued access to effective and safe treatments for all patients within Europe. The aim of this article, the third in a series of perspectives, is to discuss potential approaches to sustain cancer care and increase patient access to treatments. Much work remains to ensure the sustainability ceiling (where costs of care exceed the benefits) is not reached. Immediate steps must be taken to avoid this, including patient education to encourage earlier diagnosis, use of treatment-response biomarkers, improving efficiency of healthcare systems, use of managed-entry agreements, introduction of value-based medicines with measurable outcomes and use of less expensive medicines. Here we discuss these potential solutions with a focus on reducing the cost of cancer drugs, using biosimilar medicines as an example. Biosimilar and generic medicines offer a costeffective treatment option that may help combat the substantially increasing costs of cancer drugs. Competition from biosimilar medicines is expected to drive a decrease in the cost of medicines, resulting in increased affordability and access to therapy, and therefore a greater number of patients could be treated. However, various barriers must be overcome to increase the uptake of biosimilar medicines and education is needed to allay misperceptions and encourage greater use.

\section{Keywords}

Sustainability, oncology, value, outcome, biosimilar

Disclosures: Gilberto Lopes, Nils Wilking, Wim van Harten, Klaus Meier and Steven simoens have nothing to disclose in relation to this article. Arnold Vulto reports no conflict of interest in relation to this work and no financial interest in any pharmaceutical company. His institution receives financial compensation consulting/ lecturing activities on behalf of AbbVie, Amgen, Biogen, Boehringer Ingelheim, EGA (Medicines for Europe), Mundipharma, Pfizer/Hospira, Roche and Novartis/ Sandoz/Hexal. This study involves a review of the literature and did not involve any studies with human or animal subjects performed by any of the authors.

Acknowledgments: All authors critically reviewed the manuscript and approved the final version for submission. Medical writing support was provided under the direction of the authors. Editorial assistance was provided by Amanda Pedder of Spirit Medical Communications Ltd., funded by Sandoz International GmbH.

Authorship: All named authors meet the International Committee

of Medical Journal Editors (ICMJE) criteria for authorship of this

manuscript, take responsibility for the integrity of the work as a whole,

and have given final approval to the version to be published.

open Access: This article is published under the Creative Commons Attribution Noncommercial License, which permits any non-

commercial use, distribution, adaptation and reproduction provided

the original author(s) and source are given appropriate credit.

Received: 8 June 2017

Accepted: 15 November 2017

Citation: European Oncology \& Haematology, 2017;13(2):102-7

Correspondence: Gilberto Lopes, Sylvester Comprehensive Cancer Center, University of Miami, 1475 N.W. 12th Avenue, Miami, FL 33136, US.

E: glopes.md@gmail.com

Support: The publication of this article was supported by Sandoz International $\mathrm{GmbH}$, who was given the opportunity to review the article for scientific accuracy before submission. Any resulting changes were made at the authors' discretion.

\section{Introduction}

With the growing burden of cancer, sustainable solutions are urgently required to ensure access to effective and safe treatments for all patients. ${ }^{1}$ Health expenditure on cancer in Europe more than doubled between 1995 and 2014, increasing from €35.7 billion to €83.2 billion; high-cost cancer drugs are the main drivers of this increase in many countries. Every patient has the right to benefit from medical treatment, regardless of financial means, gender or nationality, ${ }^{3}$ but at the current rate of spending this will not be achievable in the near future.

A multidisciplinary and multipathway approach facilitated by experts in hospital pharmacy, health economics and oncology is needed. To explore current issues and potential solutions, experts in these fields from across Europe have collaborated on a series of perspectives. The current situation and consequences of reaching the sustainability ceiling (where costs of treatment outweigh the benefits), including definitions of sustainability and value, are discussed further in the first and second articles in this series of three perspectives. ${ }^{4,5}$

To regulate spending and allow continued - or even improved - access to cancer treatments, changes must be made before the sustainability ceiling is reached. ${ }^{4,5} \mathrm{As}$ detailed in the first two articles of this series, the continuing exponential rise in costs is driven, in part, by the introduction of a large number of new, high-cost treatments. Although innovation and research into new treatments should be encouraged, additional focus is needed on value-based medicine, characterised by evidence-based medicine, patient-centred care and cost-effectiveness. ${ }^{4,6}$ The availability of additional safe, effective and affordable value-based options will enable health systems to expand access to beneficial treatments for more patients, free up resources for access to other medicines, and relieve pressure on healthcare budgets?

In this third perspective, we focus on solutions, providing potential options for sustaining cancer care and increasing access to treatments 
for all patients. In particular, we provide detail on reducing the costs associated with cancer drugs, with a specific focus on the role of biosimilar medicines.

\section{The approach to sustaining cancer care is multifaceted}

There are several possible ways to sustain cancer care and aid access to new medicines (Figure 1).

\section{Increased efficiency of healthcare systems}

In 2005, the 58th session of the World Health Assembly endorsed a resolution urging member states to work toward sustainable health financing, with a view to achieving 'universal coverage' (defined as access to key promotional, preventive, curative and rehabilitative health interventions for all at an affordable cost, thereby achieving equity in access). ${ }^{8}$

To achieve this goal, the most efficient ways to meet the challenges faced by health systems must be identified and fundamental changes implemented. According to the World Health Organization, all countries can act to improve the efficiency of their health systems, releasing resources that could be used to increase access to treatment, improve or increase service provision, and reduce costs. Unnecessary spending on medicines is listed among the ten leading sources of inefficiency, with key drivers including underuse of generics, as well as higher than necessary prices for medicines. Some medicines are nearly always sold at substantial markups compared with production costs, and prices vary significantly from country to country. These inefficiencies could be addressed by: improving prescribing guidance; requiring, permitting or offering incentives for generic substitution; developing active purchasing-based assessment of costs and benefits of alternatives; ensuring transparency in purchasing and tenders; controlling excessive markups; and monitoring and publicising the prices of medicines. ${ }^{9}$

\section{Programmes to encourage prevention and early diagnosis}

A substantial proportion of cancers are preventable. Primary and secondary prevention strategies have been demonstrated to be cost effective, while also potentially reducing the number of patients with cancer in future generations requiring diagnosis, treatment and follow up. Countries should therefore integrate these measures into existing cancer care plans. ${ }^{10}$

Earlier diagnosis increases the scope for successful treatment, reducing the burden of disease. While the additional costs of screening and diagnosis may not improve sustainability in the short term, costs would be expected to reduce over time due to reduced morbidity. Furthermore, the added value to the population of life-years gained and cost per life saved suggests that in the longer term earlier diagnosis would be a costeffective solution and improve value for patients and society. ${ }^{11}$

\section{Biomarkers to identify responders and nonresponders}

Biomarkers of drug response may improve sustainability by enabling increased use of personalised medicine and reducing use of expensive drugs in patients unlikely to benefit owing to underlying disease characteristics. For example, screening for programmed cell death protein 1 (PD1) and/or programmed cell death ligand 1 (PDL1) in immunooncology enables targeted treament and reduces use of expensive PD1/ PDL1 inhibitors in patients who would not benefit. ${ }^{12}$ However, impact of biomarker screening may depend on the approval status of a drug in
Figure 1: Potential solutions to sustain cancer care and aid access to new treatments

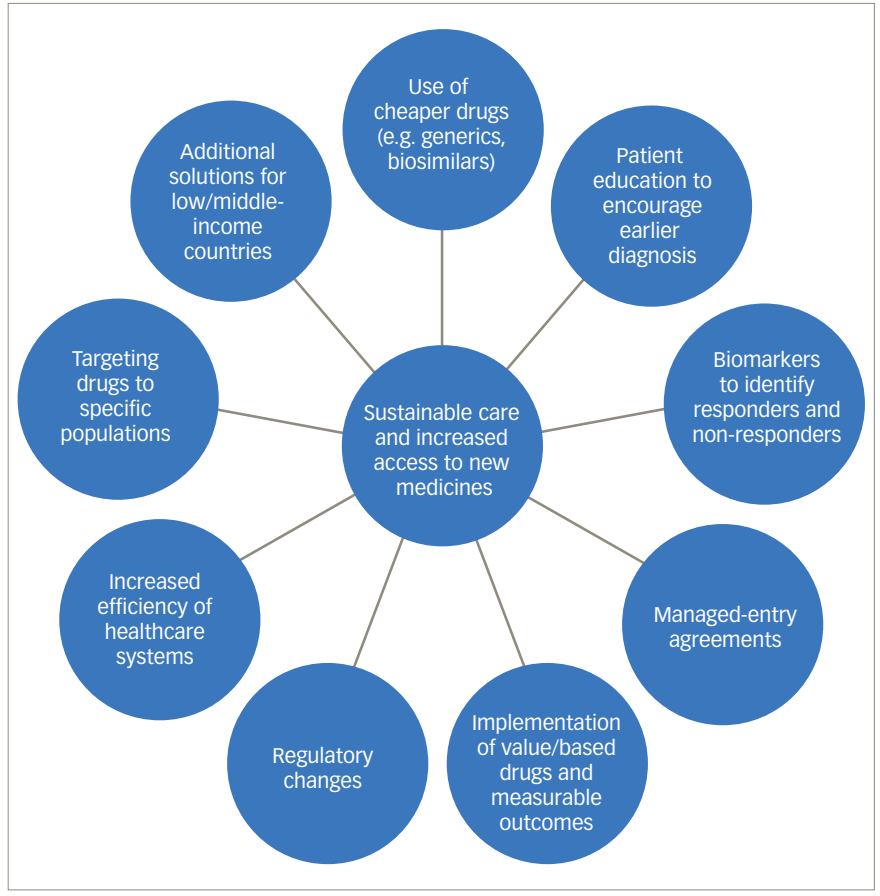

relation to the discovery of the biomarker. If biomarkers are identified before approval, manufacturers may compensate for the potentially reduced market by setting a high price for the drug. ${ }^{13}$

\section{Managed-entry agreements}

Managed-entry agreements limit reimbursement of medicines to those subpopulations that are most likely to benefit from treatment. They play a key role in controlling the impact of new medicines on budget, addressing uncertainties about the therapeutic benefit or cost effectiveness of a medicine in a real-world setting, and optimising the use of medicines through patient selection and delivery mechanisms. ${ }^{14}$ These agreements are increasingly used to obtain lower drug prices in many countries..$^{15}$ However, there are concerns that this approach may lead to limited transparency because the agreed prices and the nature of the agreements are not usually disclosed to the public.16

\section{Implementation of value-based pricing and measurable outcomes}

Innovation in drug development is not always accompanied by financial benefit or a proportionate improvement in important patient outcomes, such as survival. The average launch price of cancer drugs increased by 10\% annually between 1995 and 2013,17 yet increased survival benefit only amounted to a few months in some cases. Arguably, current coverage, reimbursement and patent policies do not encourage the development of treatments with clinically meaningful survival benefits. Between 2009 and 2013, only 35\% of cancer drugs approved by the European Medicines Agency (EMA) demonstrated prolonged survival and only $10 \%$ showed improved quality of life in published evidence. Of those without demonstration of survival benefit at market entry, only $7 \%$ and $11 \%$ reported extension of life or improved quality of life, respectively, in post-marketing studies. ${ }^{18}$ New medicines that are approved based on statistically significant data, but that do not demonstrate clinically meaningful benefit, are not of value to society. In fact, they add to the increased absolute costs to society, pushing them ever closer to becoming unaffordable. ${ }^{4}$ 
Therefore, prices paid for drugs by payers and patients may not always reflect their true value. Payers are sometimes forced to make coverage decisions based on limited information or where few alternative treatments exist. Different prices may be negotiated between drug companies and various sets of payers, and the price of one product may be determined in conjunction with negotiations over the prices and/or quantities of related products, which would result in prices of several products not reflecting their underlying value. ${ }^{19}$

Value-based pricing has been proposed as a policy that promotes access while rewarding useful innovation by assigning value to medicines based on a range of clinical and societal parameters. ${ }^{15}$ This approach could mean that insurers restrict coverage of drugs to those that improve survival time by an economically significant amount.17

Professional organisations, including the European Society of Medical Oncology (ESMO) and the American Society of Clinical Oncology (ASCO), have taken the lead in assessing the real value of treatments by creating value frameworks for drug treatments, which vary in several dimensions. ${ }^{5,20,21}$ However, there are major limitations to these frameworks, including the lack of a well-defined theoretical basis for determining value and the absence of analyses relating to how payers, physicians or patients would make decisions based on the available metrics. ${ }^{19}$ One of the challenges in assessing treatment value is how to measure and compare health outcomes and costs. The concept of a threshold value, i.e. how much an individual or society is willing to pay for an incremental health gain, could be used for the valuation of various dimensions of treatment., ${ }^{5,19}$ However, allocative value (the distribution of assets among population subgroups), technical value (how well assets are used among those in need) and personalised value (how well decisions relate to individuals' values) should also be considered. ${ }^{22}$ It is also important to understand that reducing overall costs may sometimes necessitate increasing spending for some services to enable a reduction in others. ${ }^{23}$

\section{Regulatory changes}

Regulatory approval remains a critical step in getting a drug to market, but it does not guarantee market access. Recommendation for reimbursement represents an additional hurdle to market entry in many countries. Pharmaceutical drugs, medical technology or biotechnology products must meet four criteria for reimbursement: quality, efficacy, safety and cost effectiveness. ${ }^{24}$ This demonstration of clinical and/or monetary benefit is important for market-access schemes aimed at improving access to effective therapies for all patients.

Regulators are not directly involved in determining the price of new medicines; however, they are involved in the ongoing debate over the cost of medicines. Regulatory requirements contribute to high pharmaceutical research and development costs, while regulatory approval in protected markets allows drug manufacturers to charge higher prices. For the sake of affordability, regulators should not yield to pressure to lower standards but should equally be aware of budget pressures from newly-approved drugs. ${ }^{24}$ Unfortunately, due to the requirements for population selection in preregistration trials, the value of newly-approved drugs is not known at market entry. Standard clinical trials may, therefore, not be best suited for a proper assessment of the societal value of a new medicine.

There are several ways that regulators can contribute to maintaining sustainable expenditure on cancer drugs in Europe. They can encourage clinical trials that measure value and promote better design and more efficient conduct of clinical trials. Health technology assessment (HTA) bodies state that clinical trials supporting marketing authorisation often fail to provide adequate data on quality-of-life or healthcare resource utilisation. To bridge this gap, the EMA and some EU member states have held advice sessions at which regulators, HTA experts and drug developers discussed premarketing clinical trial designs. Regulators in some countries can also facilitate data collection by considering payers' needs when requesting post-approval studies. ${ }^{24}$

\section{The role of industry}

The pharmaceutical industry can help healthcare professionals (HCPS) and policy makers to understand the differences between medicines and ensure that affordable, value-based medicines are accessible to patients. It has been proposed that the pharmaceutical industry should be rewarded for developing new drugs with better value and governments should only award market exclusivity when genuine innovation has occurred. ${ }^{25}$ The costs of research and development, marketing, production and distribution, as well as the end prices of new treatments, should be made clear. ${ }^{25}$ Where there is full transparency, a reasonable and easily understandable price can be set and reimbursed, allowing for price adjustment if market expansion develops differently than expected.

Industry can also be instrumental in generating health economics data for new drugs. Pharmacoeconomic studies should be included from the earliest development phase through to market access and subsequent loss of patent, to enable assessment of value evolution throughout the drug lifecycle; ${ }^{26}$ these data should be analysed and critiqued by independent health economics investigators. Overall survival and quality-of-life outcomes data should be collected from phase II studies onwards because payers will likely request more robust data to support HTA assessments in the future. More rigorous HTA-based guidance is needed to ensure that the industry is aware of the requirements that must be met for market access and reimbursement. This will allow for earlier planning to ensure all relevant data are collected during development to demonstrate allocative, technical and personalised value, as well as clinical benefit.

\section{Drug pricing based on economic status}

Potential solutions for low- and middle-income countries include price discrimination (e.g. through access programmes), compulsory licensing and the differential pricing of drugs based on a country's specific needs and ability to pay, which may open up opportunities for drug manufacturers to serve these markets while also demonstrating social responsibility. ${ }^{27-29}$

\section{Use of less expensive medicines}

Generic and biosimilar medicines offer the potential to improve value in healthcare ${ }^{7}$ and may help to combat the substantially increasing costs of cancer drugs, thereby increasing access to cancer treatment..$^{30}$ These less costly treatment options may give greater autonomy to physicians, enabling them to prescribe the most appropriate treatments for their patients in terms of effectiveness, costs and value.

A generic medicine matches a branded drug in terms of chemical formula, dosage, safety, strength, mode of administration, quality, performance and intended use. Generic medicines are usually chemically synthesised, allowing the existing medicine to be replicated exactly. ${ }^{31}$ Uptake varies between countries in Europe and is influenced by acceptance, brand loyalty among physicians and patients, pharmacist incentives or automatic substitution, patient cost sharing, physician prescription by 
Figure 2: Filgrastim uptake in the UK during 2004-2014

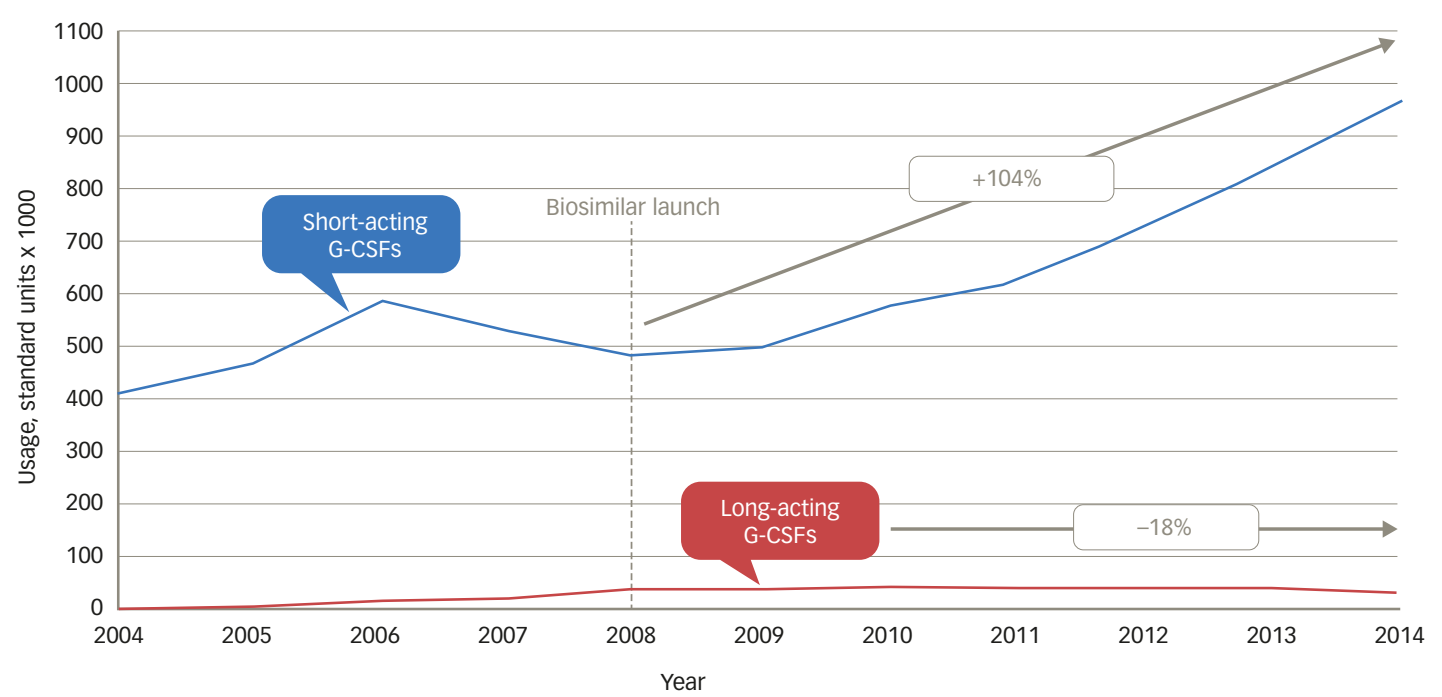

G-CSFS = granulocyte colony stimulating factors. Reproduced with permissions from IMS Institute for Healthcare Informatics.?

international non-proprietary name and price regulation. ${ }^{32,33}$ For example, France has historically been a brand-loyal market with few mechanisms to drive generic uptake, as demonstrated by the low penetration rate. ${ }^{34}$ By contrast, Germany encourages generic uptake via prescribing targets, which have driven higher market penetration. ${ }^{35}$

A biosimilar is a biologic medicine that matches a licensed reference medicine in terms of safety, purity and potency.31,36-39 There is considerable scope for increasing the use of biosimilar medicines; ${ }^{40,41}$ however, demand-side measures and general policies may be needed to change prescribing habits and realise competition in the market with subsequent cost savings. ${ }^{42}$

\section{Biosimilar medicines are a promising value- based solution Improving affordability of cancer care}

Biosimilar medicines that have comparable clinical outcomes to reference biologic medicines but at lower cost could enable many more patients with cancer to access effective therapies. ${ }^{43}$ The availability of biosimilar medicines is expected to improve affordability of cancer care worldwide. ${ }^{44}$ Evidence shows that the introduction of biosimilar medicines in Europe at reduced prices led to competitive price reductions in reference medicines and beyond. .045 For example, Norway's price regulator was offered a discount of $72 \%$ for biosimilar infliximab in the country's 2015 tender for drugs. ${ }^{46}$ In Germany, three epoetin biosimilar medicines were introduced in 2008 at a cost of $30 \%$ below the reference medicine price. A price reduction in the reference medicine was followed by further price reductions of the biosimilar medicines. ${ }^{47}$

In the UK, Germany and the Netherlands, the availability of a lower cost biosimilar filgrastim (a granulocyte-colony stimulating factor [G-CSF] for treatment of infection and neutropenic fever during chemotherapy) correlated with a 10-20\% increase in overall use, mainly occurring earlier in the course of therapy. ${ }^{48}$ In the UK, guidance for the use of GCSFs was updated after the launch of biosimilar filgrastim to reflect the improved cost effectiveness of the biosimilar versus the reference medicine. As a result, the recommendation for G-CSF initiation was changed from second- to first-line cancer treatment. Uptake of short-acting filgrastim (biosimilar and reference) increased by 104\% in the UK between 2008 and 2014 (see Figure 2), representing a significant cohort of patients who may not otherwise have had access to this medicine.?

\section{Potential impact of biosimilar medicines on the price of cancer drugs}

The markets best-placed to capitalise on the benefits of biosimilar medicines are those with a functioning competitive environment, where manufacturers are motivated to participate over the longer term and physicians are at the heart of the decision-making process.? Biosimilar medicines enable stakeholders to benefit from a greater choice of treatments. Competition from biosimilar medicines will contribute to lower drug costs and enable healthcare systems to make significant savings that can be reinvested to tackle the expected increase in cancer prevalence, as well as drive pharmaceutical innovation. ${ }^{35}$ Savings in the top five European markets could exceed €10 billion between 2016 and 2020, based on direct competition with reference medicines and excluding indirect competition for other in-class or therapy-area-specific product sales.? By rapidly approving generics and biosimilar medicines, regulators can facilitate competition, driving down prices. A recent information guide for HCPs prepared jointly by the EMA and the European Commission states that biosimilar competition can offer advantages to European healthcare systems as it is expected to improve patient access to safe and effective biological medicines with proven quality. ${ }^{49}$

\section{Potential barriers to the uptake of biosimilar medicines and suggested solutions}

Guidance from the EMA states that 10 years of clinical experience has shown biosimilar medicines approved by the EMA can be used as safely and effectively in all their approved indications as reference biologic medicines. ${ }^{49}$ Despite this and the potential for substantial cost savings, biosimilar medicines face similar challenges to generics in achieving market penetration.

As biosimilar medicines are still not universally accepted, there is considerable variation in uptake.40,41,50 In 2013, the uptake of biosimilar filgrastim in the five largest European oncology drug markets (France, Germany, Italy, Sweden and the UK) ranged from 35\% in France to $91 \%$ in Sweden, while uptake of epoetin varied from $16 \%$ in France to $53 \%$ in Germany. ${ }^{51}$ 
Table 1: Physicians' perceptions and concerns about biosimilars and potential solutions

\begin{tabular}{|c|c|}
\hline Physicians' perception/concern & Response/potential solution \\
\hline $\begin{array}{l}\text { Fear of low quality or substandard biosimilar } \\
\text { medicines }^{55}\end{array}$ & $\begin{array}{l}\text { - The manufacturing process for a biosimilar must comply with the same pharmaceutical quality } \\
\text { requirements as any new biologic and pharmaceutical companies must demonstrate that the } \\
\text { manufacturing process is capable of consistently producing a high-quality product (as defined by } \\
\text { strict GMP-standards). }{ }^{39} \\
\text { - Regulatory guidelines for development and approval of biosimilar medicines are rigorous and } \\
\text { undergo constant refinement. }\end{array}$ \\
\hline $\begin{array}{l}\text { Indication extrapolation } \\
\text { - concerns over extrapolation of clinical data (e.g. to } \\
\text { other indications or patient groups in which trials have } \\
\text { not been conducted). }\end{array}$ & $\begin{array}{l}\text { - A biosimilar may be approved for all licensed indications of the reference medicine, without the } \\
\text { need for clinical data in those indications, offering the potential for cost savings and wider patient } \\
\text { access. } \\
\text { - Extrapolation of data requires sound scientific justification and does not imply a lower level } \\
\text { of reassurance with regard to the efficacy and safety for the biosimilar than the reference } \\
\text { medicine.39,56 } \\
\text { - However, differences in efficacy and safety risk may exist between indications; therefore, a } \\
\text { cautious approach to selection of patient populations may be warranted, particularly where the } \\
\text { mechanism of action may differ. } \\
\text { - Therapeutic equivalence implies that the biosimilar does not have better or worse efficacy than the } \\
\text { reference medicine, allowing the use of the same dosage for the same indication. }{ }^{39,56}\end{array}$ \\
\hline $\begin{array}{l}\text { Efficacy } \\
\text { - Concerns about reduced efficacy. } \\
\text { - The basis for considering the efficacy of a biosimilar } \\
\text { to match that of the reference medicine has been } \\
\text { questioned. }\end{array}$ & $\begin{array}{l}\text { - There is a common misperception that biosimilar medicines have reduced efficacy compared } \\
\text { with the reference medicine. However, approval of a biosimilar relies on demonstration of } \\
\text { 'comparability' or 'no clinically meaningful differences' in efficacy versus the reference biologic } \\
\text { (see 'Demonstration of comparability' above). }{ }^{30,39,49}\end{array}$ \\
\hline $\begin{array}{l}\text { Safety } \\
\text { - Fears of unexpected adverse events. } \\
\text { - concerns that safety databases for biosimilar medicines } \\
\text { could be insufficient at the time of approval, with } \\
\text { immunogenicity being a particular concern. }\end{array}$ & $\begin{array}{l}\text { - For biosimilar medicines, an extensive comparability exercise with the reference medicine is } \\
\text { required (see 'Demonstration of comparability' above), including human efficacy and safety data. } \\
\text { Biosimilar development can involve reference to the safety experience gained with the reference } \\
\text { medicine. The risk of new (serious) adverse effects after licensing is considered much lower } \\
\text { for a biosimilar than for a biologic containing a new or modified active substance. }{ }^{39,49} \text { To date, } \\
\text { track records for biosimilar medicines show them to be no more immunogenic than reference } \\
\text { medicines. }{ }^{57} \\
\text { - Immunogenicity is an ongoing concern for all biologic medicines, not just biosimilar medicines. } \\
\text { Human immunogenicity data are required to exclude a marked increase in immunogenicity of the } \\
\text { biosimilar versus the reference medicine. } \\
\text { - Strict post-marketing surveillance and large post-marketing studies are needed for complete } \\
\text { reassurance of safety of biosimilar medicines. }{ }^{39}\end{array}$ \\
\hline $\begin{array}{l}\text { Switching/transitioning } \\
\text { - Lack of switch trials and safety and efficacy concerns } \\
\text { over switching patients from reference medicine to } \\
\text { biosimilar. }\end{array}$ & $\begin{array}{l}\text { - Switching to a biosimilar does not reduce efficacy. }{ }^{14,58} \\
\text { - Changes in safety and efficacy might be associated with a switch if either the reference or } \\
\text { biosimilar medicine has higher inter-individual pharmacokinetic variation; however, this has not } \\
\text { been observed for biosimilar or reference medicines to date. }{ }^{32} \\
\text { - Immunogenicity caused by a switch is highly unlikely with licensed biosimilar medicines because } \\
\text { they have been shown to match the structure and immunogenicity of their reference medicines in } \\
\text { pre-registration clinical trials. }{ }^{59} \\
\text { - Switching from reference to biosimilar somatropin, epoetin alfa and insulin glargine molecules } \\
\text { have not indicated a risk for adverse effects. }{ }^{59}\end{array}$ \\
\hline
\end{tabular}

GMP = good manufacturing practice.

The understanding of biosimilar medicines varies by country and region, and while confidence is growing, concerns remain around the true equivalence of a biosimilar to its reference medicine, as well as immunogenicity, efficacy and safety (Table 1). ${ }^{52}$ There is often uncertainty about the interchangeability of biosimilar and reference medicines, which is fuelled by variation in definitions and guidance between the EMA and FDA. ${ }^{53}$ Furthermore, questions have been raised about who will ultimately benefit from associated cost savings.
Physicians, patients and payers require balanced education on biosimilar medicines and their role in treatment, while payers need to ensure that physicians and manufacturers are properly incentivised to drive uptake of biosimilar medicines. ${ }^{7.54}$

Delayed approval and uptake of biosimilar medicines in oncology may have substantial impact on costs and patient access to care. Incentives at a national, regional and local level may be required to promote 
uptake of biosimilar medicines and utilisation of treatments with the lowest cost.

\section{Conclusions}

The biggest threat to sustainability remains continued use of nonvalue-based therapies. Multidisciplinary, multipathway approaches are needed to achieve sustainable cancer care in Europe. The immediate implementation of initiatives to sustain cancer care should allow continued, and ideally increased, access to effective and safe treatments for all patients. Regulatory bodies, healthcare systems and industry must implement fundamental changes to clarify differences between medicines and ensure that affordable, value-based medicines are available. Furthermore, HCPS should lead the value debate; experts in hospital pharmacy, health economics and medical oncology should collaborate to promote efficiencies and facilitate continued and increased access. Potential savings must be reinvested into improving treatments to ensure patients ultimately benefit, and physicians need to be reassured of this by regulators, payers and industry if they are to lead the value debate.

The development of new cancer treatments that are less costly and offer greater benefit should be encouraged as part of a multipathway plan to secure continued access to effective and safe cancer treatments. Generic and biosimilar medicines represent cost-effective treatment options that may enable payers to give greater autonomy to physicians, providing them with the freedom to prescribe the most appropriate treatments for their patients. Competition from biosimilar medicines is expected to increase affordability and improve access to therapy, enabling the treatment of a greater number of patients. Delayed uptake of biosimilar medicines could have substantial cost and access consequences. Competition lies at the heart of the biosimilar value proposition; however, it must be noted that not all markets have a functioning competitive environment, so are not in a position to benefit from forthcoming biosimilar medicines within oncology. Examining market penetration in individual countries will identify where educational initiatives would be beneficial to allay misperceptions and encourage greater use of generic and biosimilar medicines.

Much work remains to ensure that the sustainability ceiling is not reached and costs of care do not outweigh the benefits. Collaboration among stakeholders in all countries is needed so that sustained access to oncology medicines becomes a reality for all patients within Europe.
1. Coleman $\mathrm{CN}$, Formenti SC, Williams TR, et al., The international cancer expert corps: a unique approach for sustainable cance care in low and lower-middle income countries, Front Oncol, 2014;4:333.

2. Jönsson B, Hofmarcher T, Lindgren P, et al., The cost and burden of cancer in the European Union 1995-2014, Eur J Cancer 2016;66:162-70

3. European Commission, European Patients' Rights Day: 10 benefits the EU brings to patients, 2014. Available at: http:// europa.eu/rapid/press-release_MEMO-14-341_en.htm (accessed 17 November 2017)

4. Wilking N, Lopes G, Meier K, et al., Can we continue to afford access to cancer treatment?, European Oncology and Haematology, 2017;13:Epub ahead of print.

5. Simoens S, van Harten W, Lopes G, et al., What happens when the cost of cancer care becomes unsustainable? European Oncology and Haematology, 2017:13:Epub ahead of print.

Oncology and Hed

Epidemiol Health, 2015;37:e2015014.

7. IMS Institute for Healthcare Informatics, Delivering on the potential of biosimilar medicines: the role of functioning competitive markets, 2016. Available at: www.iqvia.com/media/iqvia/pdfs/institute-reports/delivering-on-the-potentialmedia/iqvia/pdfs/institute-reports/delivering-on-the-po
of-biosimilar-medicines.pdf (accessed 22 Nov 2017). of-biosimilar-medicines.pdf (accessed 22 Nov 2017).
World Health Organization, WHA58.33 Sustainable health

8. World Health Organization, WHA58.33 Sustainable health financing, universal coverage and social health insurance. Fiftyeight World Health Assembly Document 58/20, 2005. Available at: http://apps.who.int/medicinedocs/documents/s21475en/ s21475en.pdf (accessed 17 November 2017).

9. World Health Organization, Chapter 4: More health for the money. In: The world health report: health systems financing: the path to universal coverage, 2010. Available at: wwwwho int/whr/2010/10_chap04_en.pdf (accessed 17 November 2017).

10. Bray F, Jemal A, Torre LA, et al., Long-term realism and cost-effectiveness: primary prevention in combatting cance and associated inequalities worldwide, I Natl Cancer Inst, and associated in:

11. UK Department of Health, The likely impact of earlier diagnosis of cancer on costs and benefits to the NHS. Summary of an economic modelling project carried out by Frontier Economics on behalf of the Department Of Health National Awareness and Early Diagnosis Initiative (NAEDI) (January 2011), London: Department of Health, 2011. Available at: www.gov.uk government/uploads/system/uploads/attachment_data/ file/213788/dh_123576.pdf (accessed 17 November 2017).

12. Meng $X$, Huang $Z$, Teng F, et al., Predictive biomarkers in PD-1/ PD-L1 checkpoint blockade immunotherapy, Cancer Treat Rev 2015;41: 868-76.

13. Trusheim MR, Berndt ER, Douglas FL, Stratified medicine: strategic and economic implications of combining drugs and strategic and economic implications of combining drugs

14. Siviero PD, Managed-entry agreements as a way of enabling patient access to innovation, European Journal of Oncology patient access to innovation,

15. Vogler S, Paris V, Ferrario A, et al., How can pricing and reimbursement policies improve affordable access to medicines? Lessons learned from European countries, App Health Econ Health Policy, 2017;15:307-21.

16. Vogler S, Vitry A, Babar ZU, Cancer drugs in 16 European countries, Australia, and New Zealand: a cross-country price comparison study, Lancet Oncol, 2016;17:39-47.

17. Howard DH, Bach PB, Ernst R, et al., Pricing in the market for anticancer drugs, J Econ Perspect, 2015;29:139-62.

18. Davis $\mathrm{C}$, Naci H, Gurpinar E, et al., Availability of evidence of benefits on overall survival and quality of life of cancer drugs approved by European Medicines Agency: retrospective cohort study of drug approvals 2009-13, BMJ, 2017;359: j4530.

19. Walton SM, Basu A, Mullahy J, et al., Measuring the value of pharmaceuticals in the US health system, Pharmacoeconomics, 2017:35:1-4.

20. Cherny NI, Sullivan R, Dafni U, et al., A standardised, generic validated approach to stratify the magnitude of clinical benefit that can be anticipated from anti-cancer therapies: the European Society for Medical Oncology Magnitude of Clinical Benefit Scale (ESMO-MCBS), Ann Oncol, 2015;26:1547-73.

21. Schnipper LE, Davidson NE, Wollins DS, et al., Updating the American Society of Clinical Oncology value framework: revisions and reflections in response to comments received, J Clin Oncol, 2016;34:2925-34.

22. Kerr DJ, Jani A, Gray M, Strategies for Sustainable Cancer Care, 2016. Available at: http://meetinglibrary.asco.org/record/50670/ edbook (accessed 17 November 2017).

23. Porter ME, What is value in healthcare?, N Eng/ J Med, 2010;363:2477-81.

24. Eichler $\mathrm{HG}$, Hurts $\mathrm{H}$, Broich $\mathrm{K}$, Rasi $\mathrm{G}$, Drug regulation and pricing - can regulators influence affordability?, N Eng/ J Med, 2016;374:1807-9.

25. UN Secretary-General and Co-Chairs of the High-Level Panel on Access to Medicines, Promoting innovation and access to health technologies, 2016. Available at: https://static1. squarespace.com/static/562094dee4b0d00c1a3ef761/t/57d7 4b232994ca43043e01b4/1473727274910/HLP+Factsheet.pdf (accessed 17 November 2017).

26. Simoens $\mathrm{S}$, Health economics of market access for biopharmaceuticals and biosimilars, J Med Econ, 2009;12:211-18.

27. Lopes Gde L Jr, de Souza JA, Barrios C, Access to cancer medications in low- and middle-income countries, Nat Rev Clin Oncol, 2013;10:314-22.

28. Yadav P, Differential Pricing for Pharmaceuticals. Review of current knowledge, new findings and ideas for action, 2010 Available at: http://apps. who.int/medicinedocs/documents/ Available at. http.//apps.Who.int/medicinedocs/documents/s18390en.pdf. (accessed 17 November 2017). 29. Rémuzat C, Tavella F, Toumi M, Differential pricing for pharmaceuticals: Overview of a widely debated pricing concept and key challenges, Value Health, 2015;18:A526.

30. Leung LK, Mok K, Liu C, Chan SL, What do oncologists need to know about biosimilar products?, Chin I Cancer 2016;35:91.

31. Rugo HS, Linton KM, Cervi P, et al., A clinician's guide to biosimilars in oncology, Cancer Treat Rev, 2016;46:73-9.

32. Costa-Font J, Rudisill C, Tan S, Brand loyalty, patients and limited generic medicines uptake, Health Policy, 2014;116:224-33.

33. Dylst P, Vulto A, Godman B, Simoens S, Generic medicines: solutions for a sustainable drug market?, Appl Health Econ Health Policy, 2013;11:437-43.

34. Dylst $P$ Vulto $A$, Simoens $S$, Analysis of French generic medicines retail market: why the use of generic medicines is limited, Expert Rev Pharmacoecon Outcomes Res, 2014:14:795-803.

35. IMS Institute for Healthcare Informatics, Global oncology trend report, A review of 2015 and outlook to 2020. Available at: www.iqvia.com/-/media/iqvia/pdfs/institute-reports/global oncology-trend-report-2016. pdf (accessed 22 Nov 2017).

36. Schneider $\mathrm{CK}$, Biosimilars in rheumatology: the wind of change, Ann Rheum Dis, 2013;72:315-8.

37. Kadam V, Bagde S, Karpe M, Kadam V, A comprehensive overview on biosimilars, Curr Protein Pept Sci, 2016;17:756-61.

38. Curigliano G, O'Connor DP, Rosenberg JA, Jacobs I, Biosimilars: extrapolation for oncology, Crit Rev Oncol Hematol, 2016;104:131-7.

39. Weise M, Bielsky MC, De Smet K, et al ., Biosimilars: what clinicians should know, Blood, 2012;120:5111-7.
40. QuintilesIMS Institute, The impact of biosimilar competition in Europe, 2017. Available at: www.medicinesforeurope.com/ wp-content/uploads/2017/05/IMS-Biosimilar-2017_V9.pdf. (accessed 17 November 2017).

41. Scott Morton FM, Stern AD, Stern S, The impact of the entry of biosimilars: evidence from Europe. Working Paper 16-141, Boston MA, USA: Harvard Business School, 2017. Available at: www.hbs. edu/faculty/Publication\%20Files/16-141_4eabf1b6-c408-4fa3a2e2-a4229a848a60.pdf (accessed 17 November 2017).

42. Moon JC, Godman B, Petzold M, et al., Different initiatives across Europe to enhance losartan utilization post generics: impact and implications, Front Pharmacol, 2014;5:219.

43. Bauchner H, Fontanarosa PB, Golub RM, Scientific evidence and financial obligations to ensure access to biosimilars for cancer treatment, JAMA, 2017:317:33-4.

44. Schellekens H, Smolen JS, Dicato M, Rifkin RM, Safety and efficacy of biosimilars in oncology, Lancet Oncol, 2016;17:e502e509.

45. Cornes $P$, The economic pressures for biosimilar drug use in cancer medicine, Target Oncol, 2012;7 Suppl 1:S57-67.

46. GaBi Online, Huge discount on biosimilar infliximab in Norway, 2015. Available at: www.gabionline.net/Biosimilars/General/ Huge-discount-on-biosimilar-infliximab-in-Norway (accessed 17 November 2017)

47. Mattison N, Mestre-Ferrandiz J, Towse A (eds), Biosimilars: how much entry and price competition will result?, London: Office of Health Economics (OHE), 2010. Available at: www. ohe.org/publications/biosimilars-how-much-entry-and-pricecompetition-will-result (accessed 17 November 2017).

48. Henry D, Taylor C, Pharmacoeconomics of cancer therapies: considerations with the introduction of biosimilars, Semin Oncol, 2014;41 Suppl 3:S13-20

49. European Medicines Agency, European Commission, Biosimilars in the EU: Information guide for healthcare professionals, London: EMA, 2017. Available at: http://www.ema.europa.eu/ docs/en_GB/document_library/Leaflet/2017/05/WC500226648. pdf (accessed 17 November 2017)

50. Moorkens E, Jonker-Exler C, Huys I, et al., Overcoming barriers to the market access of biosimilars in the European Union: the case of biosimilar monoclonal antibodies, Front Pharmacol, 2016;7:193

51. Renwick MJ, Smolina K, Gladstone EJ, et al., Postmarket policy considerations for biosimilar oncology drugs, Lancet Oncol, 2016;17:e31-8

52. Danese S, Fiorino G, Raine T, et al., ECCO position statement on the use of biosimilars for inflammatory bowel disease - an update, I Crohns Colitis, 2017;11:26-34.

53. Dylst P, Vulto A, Simoens S, Barriers to the uptake of biosimilars and possible solutions: a Belgian case study, Pharmacoeconomics, 2014;32:681-91.

54. Cohen H, Beydoun D, Chien D, et al., Awareness, knowledge, and perceptions of biosimilars among specialty physicians, $A d v$ Ther, 2017;33:2160-72.

55. van Vollenhoven $\mathrm{R}$, How can the proliferation of biosimilars impact on R\&D and quality?, Ann Rheum Dis, 2016;75:11. Abstract SP0038.

56. Weise M, Kurki P, Wolff-Holz E, et al., Biosimilars: the science of extrapolation, Blood, 2014;124:3191-6.

57. Kurki P, van Aerts L, Wolff-Holz E, et al., Interchangeability of biosimilars: a European perspective, BioDrugs, 2017:31:83-91. Dörner T, Strand V, Cornes $\mathrm{P}$, et al. The changing landscape of biosimilars in rheumatology, Ann Rheum Dis, 2016:75:974-82.

59. Finnish Medicines Agency, Interchangeability of biosimilars Position of Finnish Medicines Agency 2015 Available at: um Position of Finnish Medicines Agency, 2015. Avallable at: wW vaihtokelpoisuus EN. pdf (accessed 17 November 2017). 